\title{
Application of the ADINA Software for Tasks of Educational and Technical Practice
}

\author{
Veronika Valašková, Jozef Vlček, \\ University of Žilina \\ Univerzitná 8215/1, 01026 Žilina \\ Slovak Republic
}

Received: July 20, 2021. Revised: September 6, 2021. Accepted: September 8, 2021.

Published: September 10, 2021.

\begin{abstract}
Development of the designing process in civil engineering brings the possibility for more complex analysis of the structures. Computational software can be helpful for regular design but also for identification and solving of more specified problems. Finite Element Method (FEM) became one of the most used numerical methods. Numerous commercial programs are based on this method. However, these programs are more complex and require skilled designer to fully utilize their potential. This article brings the lead to apply the FEM method implemented in commercial software ADINA to solve the problem of structural mechanics. It is necessary to connect the theoretical approach of FEM modeling and experience from real case problems. Skilled designer can calibrate the numerical model to obtain relevant outputs. However, certain cases still require a detailed and individual approach during designing that is verified by the in-situ monitoring and observation. Lead of the student to the flexible treatment of the design is one of the important tasks of the educational process. This involves the basic knowledge about appropriate analysis of the problem for effective utilization of the computational software for particular applications even for more complex solutions.
\end{abstract}

\section{Keywords-ADINA, Bathe's method, FEM, Pasternak.}

\section{INTRODUCTION}

$\mathrm{T}$ he University of Žilina has an accredited field of study Civil Engineering at the Faculty of Civil Engineering. Within this field of study, students are taught at the bachelor's and master's level of education. As part of the engineering study, it is necessary to complete the compulsory subject: Finite methods of mechanics. The syllabus of this course is to learn to independently create numerical models in the Adina software and the subsequent analysis of the results obtained from these computational models.

ADINA is a commercial engineering simulation software program that is developed and distributed worldwide. The company was founded in 1986 by Dr. Klaus-Jürgen Bathe and is headquartered in Watertown, Massachusetts, United States. ADINA is numerical software based on Finite element method and is used in industry as well as in academia to solve structural problems, fluid problems, heat transfer, electromagnetic problems, fluid-structure interactions and thermomechanical problems [1].

Division according to numerical models in terms of their relation to time:

- stationary analyzes (static analysis)

- non - stationary analyzes (dynamic analysis).

A number of systems behave in such a way that when the ambient conditions change, a transition process takes place, during which the state parameters of the system change over time. After a certain time, the state stabilizes when the time change of the system parameters is zero. Stationary analysis solves precisely this final state, without which the transition process would be solved (taken into account). The solution is time independent.

In contrast, the goal of non-stationary analysis is to obtain the state parameters of the system as a function of time. The choice of the type of analysis is related to the goal of the solution and is decided by the problem solver. The terms static and dynamic analysis are introduced in the field of mechanics. A distinction is made between cases where inertial forces are and are not considered in the calculation. Sometimes the terms static and stationery are confused. Similarly, so stationary with the term dynamic. In most cases, this is true, but not always.

In the static analyzed of the building structure, the interaction of all its components must be taken into account: the superstructure, the foundation structure and the subsoil. The interaction of the foundation and the subsoil is often referred to as a contact task or interaction. In design practice, it cannot be required that the static calculation of the structure 
be supplemented by an equally detailed analysis of the state of stresses and deformations in the subsoil. The real subsoil is idealized. Various computational models of the subsoil are created, which are to serve for a reliable design or assessment of the superstructure and foundation structure [2].

However, the finite element method is not the only method that can effectively solve the problems of structural mechanics. The boundary element method is one of the methods used in numerical software. For efficient and fast calculation, however, we leaned towards numerical software ADINA, which is based on the principle of FEM. As a first step in modeling, it is necessary to choose the right discretization of the numerical model. In terms of dimension, the model can be planar or spatial. Both of them have their advantages and disadvantages. Therefore, it's necessary to have a thorough idea of how the model should work at the very beginning of numerical analysis and what results we are interested in engineering practice. After mastering these problems, however, numerical modeling is a great benefit and we can use it to obtain adequate results for solving individual assignments.

\section{INTRODUCTION OF NUMERICAL MODEL}

They are based on the assumption that the subsoil behaves as an isotropic elastic body, referred to as an elastic halfspace, characterized by a modulus of elasticity $E$ and a Poisson's number $v$. The stresses and strains of such a body are investigated by the methods of mathematical theory of elasticity.

When solving the problem of the structure-subsoil interaction, at first glance, it seems most advantageous to use, regardless of the model of the superstructure used, the spatial model of the subsoil. From the point of view of technical possibilities of computer technology currently used in our country, but also from the point of view of considerable discrepancy between theoretical possibilities of the model and real possibilities of geotechnical survey of physical properties of subsoil, this approach is quite unrealistic. Therefore, certain hypotheses and simplifications are introduced to solve this problem in order to reduce the three-dimensional problem by one dimension. Such a two-dimensional model is called surface models, because all the deformation characteristics they work with relate to the surface of the subsoil, more precisely to the contact area between the subsoil and the structure $[3,4]$.

\section{A. Model of Pasternak}

This subsoil model was described by Pasternak [5,6]. Model respects shear spread in the soil and the creation of the sinkhole in the vicinity of the building, Fig. 1.

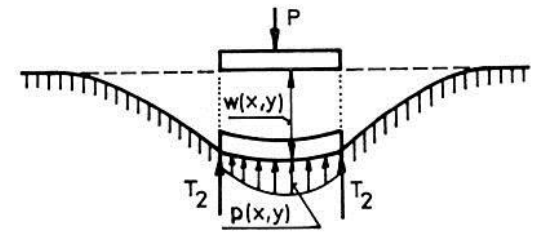

Fig. 1 Model of Pasternak
Model of Pasternak uses 2 constants $C_{1}$ and $C_{2}$. Local session constant $C_{l}$ :

$$
p_{1}(x, y)=C_{1} \cdot w(x, y)
$$

Constant $C_{2}[\mathrm{~N} / \mathrm{m}]$ of the local session:

$$
t_{x z}=C_{2} \cdot \gamma_{x z}=C_{2} \frac{\partial w(x, y)}{\partial_{x}} ; \quad t_{y z}=C_{2} \cdot \gamma_{y z}=C_{2} \frac{\partial w(x, y)}{\partial_{y}}
$$

between the intensity of the transverse shear force $t[\mathrm{~N} / \mathrm{m}]$ and the bevel $\gamma=\partial_{w} / \partial_{s}$ of the subsoil surface, characterizes the shear distribution in the soil, Fig. 2.

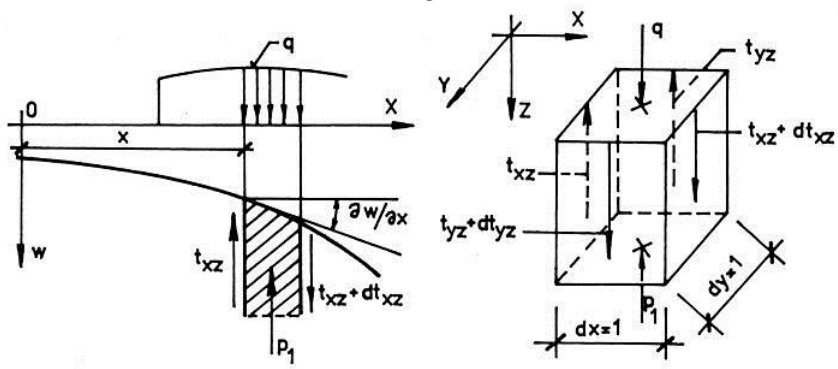

Fig. 2 The course of shear distribution in the soil For the resulting substrate reaction, $p(x, y)$ is:

$$
\begin{gathered}
p(x, y)=p_{1}(x, y)+p_{2}(x, y) \\
=p_{1}(x, y)-d t_{x z}(x, y)-d t_{y z}(x, y)= \\
=C_{1} \cdot w(x, y)-C_{2} \cdot \frac{\partial^{2} w(x, y)}{\partial x^{2}}-C_{2} \cdot \frac{\partial^{2} w(x, y)}{\partial y^{2}}
\end{gathered}
$$

\section{INTRODUCTION TO NUMERICAL SOLVER IMPLEMENTED IN ADINA}

The finite element method (FEM) is one of the best known and most common used numerical methods in engineering practice, especially in construction tasks mechanics, currents, electromagnetism, thermodynamics, etc. Calculation method FEM belongs to the group of weight residues based on Galerkin's idea variational problem. This method is based on the replacement of infinite dimensional space $v$ in the finite dimensional space $v_{n}$. Then we look for the $v_{n}$ solution in the form functions with a combination of base functions to which the following applies:

$$
\begin{aligned}
f & =\sum_{i=1}^{n} \alpha_{i} \phi_{i} \\
\int_{\Omega} L\left(u_{n}\right) \phi_{i} d \Omega & =\int_{\Omega} p \phi_{i} d \Omega, i=1, \ldots n
\end{aligned}
$$

where $L$ is a linear operator and $\Omega$ is a boundary region. Then we obtain a set of linear equations for $n$ unknown coefficients $\alpha_{i}$

$$
A_{i j} \alpha_{i j}=F_{i}
$$

where $A_{i j}$ is the stiffness matrix and $F_{i}$ is the load vector [1].

One of the biggest problems of the FEM is the creation of a network (mash). In planar problems, triangular or quadrangular elements are used. In solving 3D spatial problems, spatial elements such as pyramids, blocks, tetrahedra are used. 


\section{A. Bathe's calculation method}

Bathe's method (composite integration method) combines an explicit (Backward Euler) and an implicit (Newmark) computational method. As two independent calculation methods are combined, numerical stability of the calculation is ensured. The implicit method only is used to solve nonlinear problems, as the stability of the calculation is sufficient. In this case, the convergence of the calculation is sufficient, and it's necessary to obtain satisfactory numerical results. The essence of Bathe's calculation method is based on the division of the calculation into two-time sub-steps. In the first step the problem is solved using the Newmark method and in the second step by the Euler method. In Bathe's calculation method, the time step is divided into the exact half. In the modified Bathe method, it is possible to divide the time step variably. Due to problems with the stability of the calculation, it is possible to add most of the integration to the Newmark method and use the Euler method only as a numerical attenuation. The size of the substep is entered using the parameter $\gamma$, which is entered with rules greater than or equal to 0.5 . Bathe's method is used to use the value $\gamma=0.5$. For Newmark's method in calculating differential equations:

$$
\begin{gathered}
\left\{\dot{u}_{t_{n}}+\gamma \cdot \Delta t\right\}=\left\{\dot{u}_{t_{n}}\right\}+\left[(1-\delta) \cdot\left\{\ddot{u}_{t_{n}}\right\}+\delta \cdot\left\{\ddot{u}_{t_{n}}+\right.\right. \\
\gamma \cdot \Delta t\}] \cdot \gamma \cdot \Delta t \\
\left\{u_{t_{n}}+\gamma \cdot \Delta t\right\}=\left\{u_{t_{n}}\right\}+\left\{\dot{u}_{t} \cdot \gamma \cdot \Delta t\right\} \\
+\left[(1-2 \alpha) \cdot\left\{\ddot{u}_{t_{n}}\right\}+\left\{\ddot{u}_{t_{n}}+\gamma \cdot \Delta t\right\}\right] \cdot \frac{(\gamma \cdot \Delta t)^{2}}{2},
\end{gathered}
$$

where $\alpha$ and $\delta$ are Newmark parameters.

For Euler's method - the second substep applies:

$$
\begin{array}{r}
\left\{\dot{u}_{n}\right\}=c_{1} \cdot u_{n}+c_{2} \cdot u_{n+\gamma h}+c_{3} \cdot u_{n+1}, \\
\left\{\ddot{u}_{n+1}\right\}=c_{1} \cdot \dot{u}_{n}+c_{2} \cdot \dot{u}_{n+\gamma h}+c_{3} \cdot \dot{u}_{n+1},
\end{array}
$$

where $c_{1}, c_{2}$ and $c_{3}$ apply:

$$
\begin{aligned}
c_{1} & =\frac{1-\gamma}{\gamma \cdot \Delta t^{\prime}} \\
c_{2} & =\frac{-1}{(1-\gamma) \cdot \gamma \cdot \Delta t^{\prime}} \\
c_{3} & =\frac{2-\gamma}{(1-\gamma) \cdot \Delta t} .
\end{aligned}
$$

\section{PROCEDURE FOR CREATING AND SOLVING A NUMERICAL} MODEL

The solution to the task is a sequence of activities that may consist with the following steps:

- assignment of the task (investor, supervisor, teacher)

- analysis of the assignment and the meaning of the task

- selection of the theory to be used in solving the problem

(bars, beam elements, shells, planar stress, etc.)

- choice of solution method (analytical, numerical)

- Compilation of a complete set of input data

- compilation of a computational model (simplification to reality)

- custom solution

- processing of results and their interpretation

- decision on next steps (end or continuation).

Therefore, in order for the task to be solved correctly, the solver must have the necessary knowledge, acquired both at school and through practice or self-study. To solve your own tasks, it is necessary to have a computing tool, which is currently the most common computer with the appropriate software. Probably the most important qualities in the creation of computational models are, first of all, creative abilities, experience, feeling and intuition [7].

\section{COMMON MISTAKES WHEN CREATING A NUMERICAL MODEL}

Everyone makes mistakes. Mistake is a reality that must be taken into account. The most serious mistake is the so-called qualitative error, when the given model does not have all the important features that are essential in terms of solving the problem. Such an error is most serious because it is difficult to detect. The model behaves correctly, but does not solve the problem we are looking for [8]. The opposite of the previous error is the complexity error, where the model contains, in addition to essential properties, also insignificant properties. In the best case, the time to solve the problem is extended, in the worst case, the solution of the problem may not be obtained at all. Another type of error is a quantitative error, where the model contains all the essential properties in terms of solving the problem, but their quantitative expression is insufficient to solve the problem at a given level of resolution. A common error that occurs during the implementation of the solution is a concretization error. In practice, this means that the results obtained in numerical analysis are in many cases not correctly and specifically incorporated into the tasks of engineering practice. The model contains all the essential properties, but in its own solution an error occurs, e.g., incorrect input of input data, error in inappropriate choice of used program. This type of error is easily detectable by checking the obtained results [9].

\section{CALCULATION OF THE NUMERICAL MODEL OF THE SUBSOIL IN ADINA}

For the needs of numerical simulation, a computational model of a concrete block placed on a flexible Pasternak model was created. It is a simplified idealized planar model. This idealization is sufficient to obtain correct results with suitable accuracy. For more detailed results or a stressresponse analysis of the subsoil or the concrete block itself, it would be necessary to create a spatial numerical model.

The advantages of the planar model are:

- simplicity of the numerical model satisfactory for static analysis

- geometry created through specific points in a plane

- time-saving creation of a numerical model

- simple and concise determination of boundary conditions

- possibility to choose simpler finite elements

- simplicity of presentation of obtained results

In this case, the concrete block simulates the load on the superstructure. Flexible subsoil and springs represent a real earth environment. Material parameters, stiffness and strength characteristics of specific materials were obtained from previous works of the authors. The superstructure represented 
by the concrete block is meshed from the finite element $2 \mathrm{D}$ solid. The material parameters are as follows: $E=4.2 \times 10^{9}$ $\mathrm{Pa}, v=0.33$ and $\rho=2200 \mathrm{~kg} / \mathrm{m}^{3}$. The subsoil consists of two elements, a beam element and a spring element. The stiffness of the springs is recalculated and represents a value $K=$ $39.01137 \times 10^{5}$ and damping $c=1250$. The model is loaded by its own weight of the concrete block and it is a stationary analysis. We can state that this is a contact task. Figure 3 shows a computational model of the situation. The length of the subsoil is 10 meters, the concrete block is 4 meters length and 1 meter high. The springs are $0.2 \mathrm{~m}$ apart, and the finite element from which the concrete block is meshed has the same dimension.

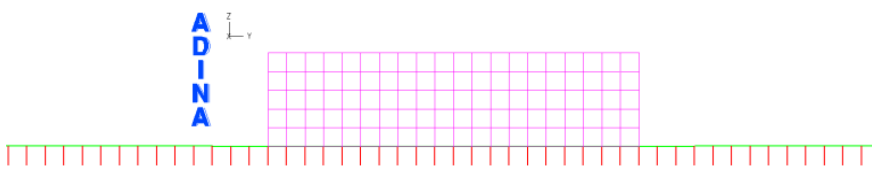

Fig. 3 Computational model in ADINA software

It is a simple static analysis in which it was used as a numerical solver based on Bathe's calculation method.

\section{A. Script creation procedure - model creation}

1. Input the basic coordinate $0 ; 0 ; 0$

2. An extension of the line that defines the subgrade surface

3. Division of the line network into finite elements

4. Creating a group of elements (elementgroups)

5. Definition of materials

6. Creating a line element network

7. Copy the line

8. Assignment of boundary conditions to the line

9. Creation of spring elements between two lines

10. Creating the geometry of a concrete block

11. Creating a concrete block line

12. Division of a network of lines into finite elements

13. Creating a concrete block network

14. Entering boundary conditions for a concrete block

15. Defining the effect of self-weight of a concrete block

16. Start the calculation

The whole program script can be found in the appendix of this article.

\section{DISCUSSION}

The calculation of the numerical model took place in 2 seconds and the results are completed and in order.

\section{A. Course of deformations in the $z$ direction}

From the given calculation model, the most interesting for us are the deformations that occur on the floor. Figure 4 shows the course of deformations and the bending line on a scale of 1: 100. The maximum deformation in $z$ direction is located directly below the concrete block and has a value of $9.29275 \times 10^{-3} \mathrm{~m}$. The area that is not loaded but is affected by the concrete block is in this case $1.74 \mathrm{~m}$ on each side.
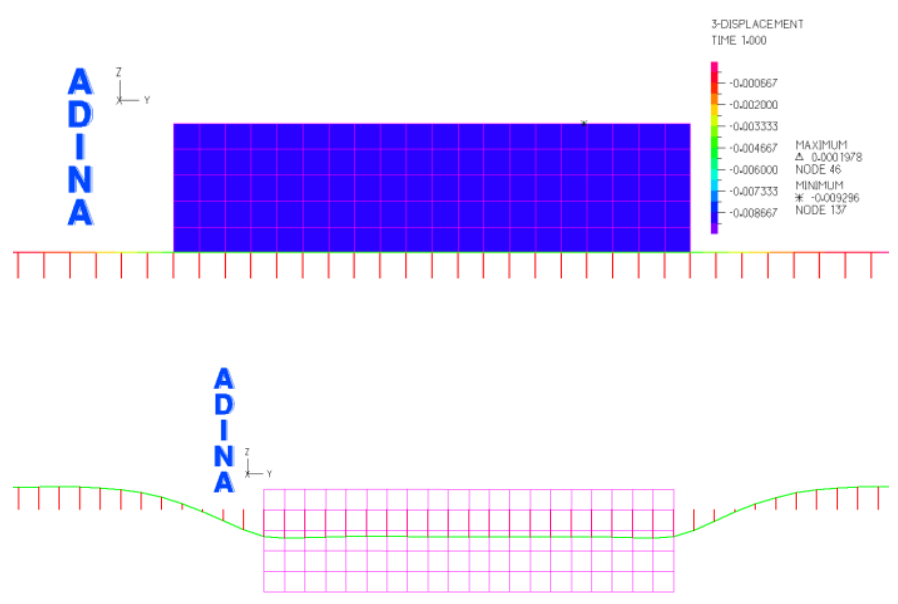

Fig. 4 Course of deformations

\section{B. Course of internal stresses}

Since this is a symmetrical problem, the stresses can be mirrored. Figure 5 shows the course of the internal stresses in the $\mathrm{xx}$ direction. It is clear from this figure, which the stress concentration occurs in the corners of the concrete block. The maximum value is $0.433 \mathrm{MPa}$. This value is safety and is out of the question affects the limit states of the concrete.

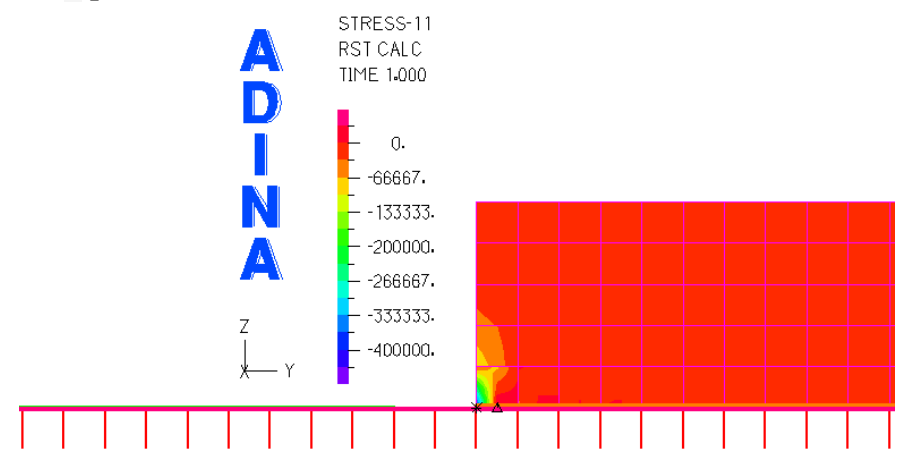

Fig. 5 Course internal stresses in $\mathrm{xx}$ direction

Figure 6 shows the course of the internal stresses in the yz direction. It is clear from this figure, which the stress concentration occurs in the corners of the concrete block. The maximum value is $0.400 \mathrm{MPa}$. This value is safety and is out of the question affects the limit states of the concrete. 


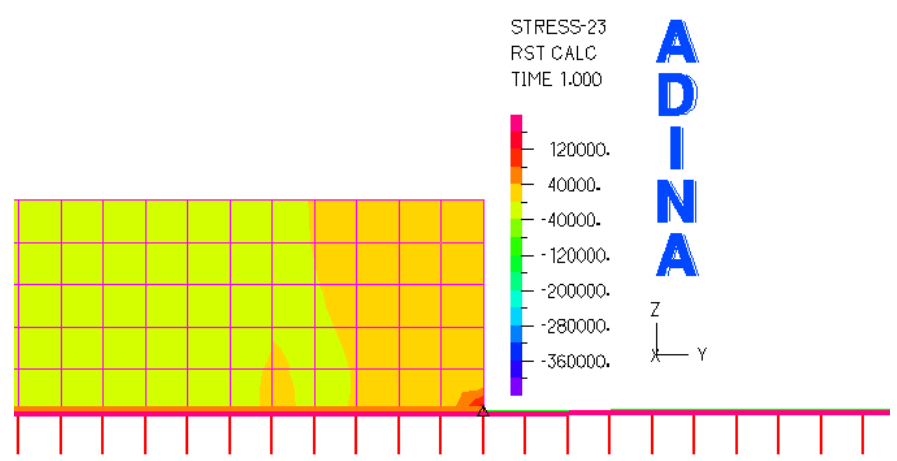

Fig. 6 Course internal stresses in yz direction

\section{Course of internal forces}

From the point of view of internal forces, the most interesting are the bending moment and contact forces on the ground arising on the subsoil. Figure 7 shows the bending moment in the y direction. The maximal bending moment occur directly under the outer corner of the concrete block and have a value $12.974 \mathrm{kNm}$. This value is also correct and in no case exceeds any limit state.

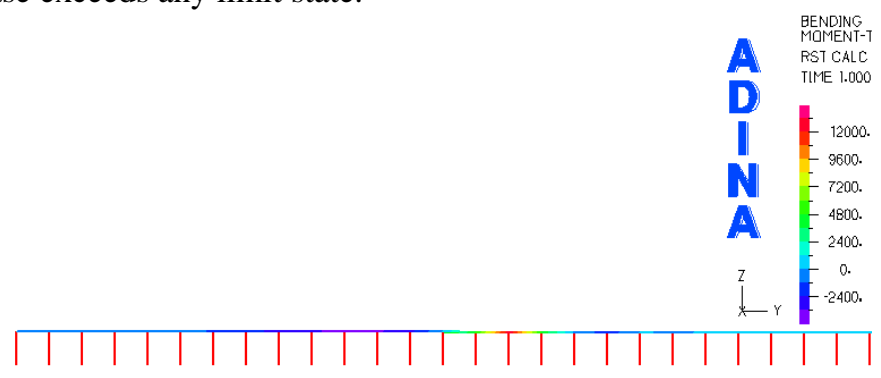

Fig. 7 Course of bending moments in y direction

Figure 8 shows the contact forces in the $\mathrm{z}$ direction. The maximal contact forces occur directly under the outer corner of the concrete block and have a value $98.161 \mathrm{kN}$. This value is also correct and in no case exceeds any limit state.

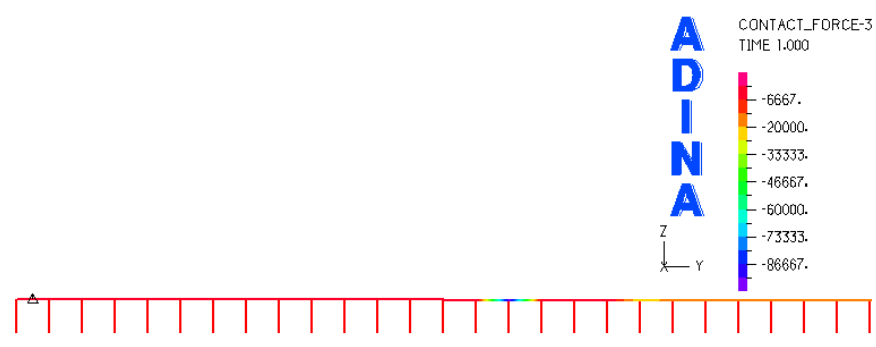

Fig. 8 Course of contact forces in $\mathrm{z}$ direction

\section{CONCLUSION}

The main aim of this article is to create the issue of numerical modeling. As finite methods of mechanics, but also the finite element method itself very actively contributes to solving the problem of applied mechanics. In principle, it is necessary to perform and follow all the steps for a correct and functional numerical model, which is possible to want to evaluate the correct results. Therefore, it is necessary to know how to decide the model as clearly as possible. ADINA enables the effective implementation of numerical calculations, replaces manual work and, within programming, forces the student to delve deeper into the essential problem and analyze the solution process in detail. Therefore, in other subjects, it is necessary to provide students with the widest possible space to take advantage of these opportunities.

Another benefit of this article is a simple demonstration of how to create a planar numerical model for the needs of static analysis of subsoil. This numerical model has to have welldefined boundary conditions so that the obtained results can be properly analyzed. As a further step and continuation of this numerical analysis, it would be appropriate to create a spatial numerical model, and compare the obtained results with each other. A large number of faculties and universities in Slovakia but also at the border, deal with the issue of numerical modeling with application to the field of study. Whereupon, it's very easy to find a large number of numerical models that are, in principle, very similar, but have different dimensions, geometry and numerical inputs. Other numerical software may be also used. This article also serves as a simple and brief explanation of the application of numerical modeling. Each student and reader can build their own numerical model according to the above procedure, verify the results and calibrate to their own proportions.

It is necessary to connect the theoretical approach of FEM modeling and experience from real case problems. Skilled designer can calibrate the numerical model to obtain relevant outputs. However, certain cases still require a detailed and individual approach during designing that is verified by the insitu monitoring and observation. Lead of the student to the flexible treatment of the design is one of the important tasks of the educational process. This involves the basic knowledge about appropriate analysis of the problem for effective utilization of the computational software for particular applications even for more complex solutions.

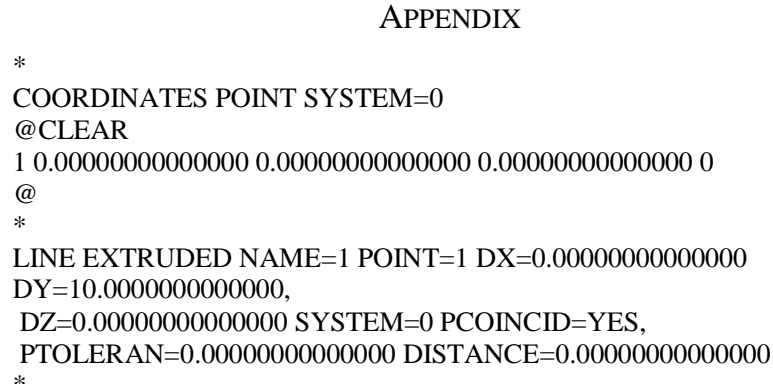


EGROUP BEAM NAME=1 SUBTYPE=THREE-D DISPLACE=DEFAULT MATERIAL $=1$ RINT $=5$,

SINT=DEFAULT TINT=DEFAULT RESULTS=STRESSES

INITIALS $=$ NONE,

CMASS $=$ DEFAULT RIGIDEND=NONE MOMENT $-\mathrm{C}=\mathrm{NO}$ RIGIDITY $=1$, MULTIPLY $=1000000.00000000$ RUPTURE $=$ ADINA OPTION=NONE, BOLT - TOL $=0.00000000000000$ DESCRIPT $=$ 'NONE' SECTION $=1$, PRINT=DEFAULT SAVE=DEFAULT TBIRTH $=0.00000000000000$, TDEATH $=0.00000000000000$ SPOINT $=2$ BOLTFORC $=0.00000000000000$, BOLTNCUR $=0$ TMC-MATE $=1$ BOLT - NUM $=0$ BOLT-

LOA $=0.00000000000000$

WARP=NO ENDRELEA $=$ ACCURATE

*

GLINE NODES $=2$ AUXPOINT $=0$ NCOINCID $=$ ENDS NCENDS $=12$,

NCTOLERA $=0.00000000000000$ SUBSTRUC $=0$ GROUP $=1$

MIDNODES $=$ CURVED,

$\mathrm{XO}=0.00000000000000 \mathrm{YO}=0.0000000000000 \mathrm{ZO}=1.00000000000000$, XYZOSYST $=$ SKEW

@CLEAR

1

@

LINE EXTRUDED NAME $=2$ POINT $=1$ DX $=0.00000000000000$

$\mathrm{DY}=0.00000000000000$,

$\mathrm{DZ}=-0.200000000000000 \mathrm{SYSTEM}=0$ PCOINCID $=\mathrm{YES}$, PTOLERAN $=0.00000000000000$ DISTANCE $=0.00000000000000$

*

LINE EXTRUDED NAME $=2$ POINT $=3$ DX $=0.00000000000000$

$\mathrm{DY}=10.000000000000$,

$\mathrm{DZ}=0.00000000000000 \mathrm{SYSTEM}=0$ PCOINCID $=$ YES,

PTOLERAN $=0.00000000000000$ DISTANCE $=0.00000000000000$

SUBDIVIDE LINE NAME $=1$ MODE $=$ LENGTH SIZE $=0.200000000000000$ @CLEAR

2

@

PROPERTYSET NAME $=1 \mathrm{~K}=3901137.00000000 \mathrm{M}=0.00000000000000$, $\mathrm{C}=1250.0000000000 \mathrm{~S}=0.00000000000000$ NONLINEA=NO

*

EGROUP SPRING NAME $=2$ PROPERTY=1 RESULTS=FORCES

NONLINEA $=\mathrm{NO}$,

SKEWSYST $=$ NO OPTION=NONE DESCRIPT='NONE'

PRINT=DEFAULT,

SAVE $=$ DEFAULT TBIRTH $=0.00000000000000$

TDEATH $=0.0000000000000$,

$6 \mathrm{DOF}-\mathrm{SPR}=\mathrm{NO}$

*

SET EGROUP NAME $=2$

TRANSFORMATI TRANSLATION NAME=1 MODE=SYSTEM

SYSTEM $=0$,

$\mathrm{DX}=0.00000000000000 \mathrm{DY}=0.00000000000000 \mathrm{DZ}=0.200000000000000$

*

SPRING LINES DUPLICAT $=$ NO NCOINCID $=$ ALL

NCTOLERA $=0.00000000000000$,

GROUP $=2$

@CLEAR

113231 'DEFAULT' 'DEFAULT' 0.000000000000000 .00000000000000 , 'SAME'

@

FIXBOUNDARY TWO-D FIXITY=ALL

@CLEAR

20 'ALL'

@

$*$

FIXITY NAME $=$ BEAM

@CLEAR

'X-TRANSLATION'

'Y-TRANSLATION'

'Y-ROTATION'

'Z-ROTATION'

'OVALIZATION'

@
FIXBOUNDARY TWO-D FIXITY=ALL

@CLEAR

20 'ALL'

10 'BEAM'

@

COORDINATES POINT SYSTEM $=0$

@ CLEAR

10.000000000000000 .000000000000000 .000000000000000

20.0000000000000010 .00000000000000 .000000000000000

$30.000000000000000 .00000000000000-0.2000000000000000$

$40.0000000000000010 .0000000000000-0.2000000000000000$

50.000000000000003 .000000000000000 .005000000000000000 @

LINE EXTRUDED NAME $=3$ POINT $=5$ DX $=0.0000000000000$

DY $=4.00000000000000$,

$\mathrm{DZ}=0.00000000000000$ SYSTEM $=0$ PCOINCID $=$ YES,

PTOLERAN $=0.0000000000000$ DISTANCE $=0.00000000000000$ *

LINE EXTRUDED NAME $=3$ POINT $=5$ DX $=0.0000000000000$

$\mathrm{DY}=0.00000000000000$,

$\mathrm{DZ}=1.00000000000000 \mathrm{SYSTEM}=0$ PCOINCID $=\mathrm{YES}$,

PTOLERAN $=0.00000000000000$ DISTANCE $=0.00000000000000$

LINE EXTRUDED NAME $=3$ POINT $=6$ DX $=0.00000000000000$

$\mathrm{DY}=0.00000000000000$,

$\mathrm{DZ}=1.00000000000000 \mathrm{SYSTEM}=0$ PCOINCID=YES,

PTOLERAN $=0.0000000000000$ DISTANCE $=0.00000000000000$

LINE POLYLINE NAME=3 TYPE=SEGMENTED

@CLEAR

50.000000000000000 .000000000000000 .00000000000000

60.00000000000000 .000000000000000 .00000000000000

80.000000000000000 .000000000000000 .00000000000000

70.000000000000000 .000000000000000 .00000000000000

50.000000000000000 .000000000000000 .00000000000000

@

EGROUP TWODSOLID NAME=3 SUBTYPE=AXISYMMETRIC

DISPLACE $=$ DEFAULT,

STRAINS=DEFAULT MATERIAL $=1$ INT $=$ DEFAULT

RESULTS=STRESSES,

DEGEN=DEFAUL FORMULAT $=0$ STRESSRE $=\mathrm{GLOBAL}$

INITIALS $=$ NONE FRACTUR=NO,

CMASS $=$ DEFAULT STRAIN-F $=0$ UL-FORMU $=$ DEFAULT $P N T G P S=0$ NODGPS $=0$,

LVUS1 $=0$ LVUS $2=0$ SED $=$ NO RUPTURE=ADINA

INCOMPAT $=$ DEFAULT,

TIME-OFF $=0.00000000000000$ POROUS $=$ NO WTMC $=1.00000000000000$, OPTION=NONE DESCRIPT $=$ 'NONE' THICKNES $=1.00000000000000$, PRINT $=$ DEFAULT SAVE=DEFAULT TBIRTH $=0.00000000000000$, TDEATH $=0.0000000000000$ TMC-MATE $=1$ RUPTURE $=0$ EM=NO JOULE $=$ NO

BODY SHEET NAME $=1$ LINE=3 DELETE-L=YES OPTION=LINE SYSTEM $=0$,

MERGE-IM=NO

SUBDIVIDE FACE NAME $=1$ BODY=1 MODE=LENGTH

SIZE $=0.20000000000000$,

MAX-SIZE $=0.00000000000000$

GFACE NODES $=9$ NCOINCID $=$ NO SUBSTRUC $=0$ GROUP $=3$ PREFSHAP=QUAD-DIRECT,

BODY=1 COLLAPSE $=$ NO SIZE-FUN=0 MIDNODES=PROJECT METHOD=DELAUNAY,

NLAYER=1 NLTABL $=0$ GEO-ERRO=0.00000000000000 $S A M P L I N G=20$, MIN-SIZE $=0.00000000000000$ AUTO-GRA=NO SIMULATE $=$ NO, DENSITY $=1.80000000000000$ EVEN=SUM FLIP=NO REFINE=ALONGNORMAL,

BLTABL $=0$ MESHING=MIXED PATTERN=AUTOMATIC 2DBLTAB=0, BLSHAPE $=2.0000000000000$

@ CLEAR 
11

@

LOAD MASS-PROPORTIONAL NAME $=1$

MAGNITUD $=9.81000000000000$,

$\mathrm{AX}=0.00000000000000 \mathrm{AY}=0.00000000000000 \mathrm{AZ}=-1.00000000000000$, INTERPRE=BODY-FORCE DESCRIPT='NONE'

APPLY-LOAD BODY=1

@CLEAR

1 'MASS-PROPORTIONAL' 1 'GROUP' $3010.000000000000000-1000$, 'NO' 0.000000000000000 .0000000000000010 'MID'

@

MASTER ANALYSIS=STATIC MODEX=EXECUTE

TSTART $=0.0000000000000$,

IDOF=110011 OVALIZAT=NONE FLUIDPOT=AUTOMATIC

CYCLICPA $=1$,

IPOSIT=STOP REACTION=YES INITIALS=NO FSINTERA=NO

IRINT=DEFAULT,

CMASS $=$ NO SHELLNDO $=$ AUTOMATIC AUTOMATI $=$ ATS

SOLVER=SPARSE,

CONTACT $-=$ CONSTRAINT-FUNCTION TRELEASE $=0.00000000000000$,

RESTART $-=$ NO FRACTURE $=$ NO LOAD-CAS=NO LOAD-PEN=NO

SINGULAR=YES,

STIFFNES $=0.000100000000000000$ MAP-OUTP $=$ NONE MAP-

FORM=NO,

NODAL-DE $="$ POROUS-C $=$ NO ADAPTIVE $=0$ ZOOM-LAB $=1$ AXIS-

$\mathrm{CYC}=0$,

PERIODIC $=$ NO VECTOR $-\mathrm{S}=$ GEOMETRY EPSI-FIR=NO STABILIZ=NO, STABFACT $=1.00000000000000 \mathrm{E}-10$ RESULTS $=$ PORTHOLE

FEFCORR=NO,

BOLTSTEP=1 EXTEND-S=YES CONVERT-=NO DEGEN=YES TMC-

MODE $=\mathrm{NO}$

IRSTEPS $=1$ INITIALT $=$ NO TEMP-INT $=$ NO ESINTERA $=$ NO

$\mathrm{OP} 2 \mathrm{GEOM}=\mathrm{NO}$,

INSITU-D=NO OP2ERCS=ELEMENT 2DPL-AX=YZ-Z

OP2STR=DEFAULT,

IRTIMES $=0$ OP2SAV=END

*

CGROUP CONTACT2 NAME $=1$ SUBTYPE $=$ DEFAULT FORCES $=$ YES

TRACTION=YES,

NODETONO $=$ NO FRICTION $=0.00000000000000$

$\mathrm{EPSN}=1.00000000000000 \mathrm{E}-12$,

EPST $=0.00000000000000$ DIRECTIO $=$ NORMAL CONTINUO $=$ YES, INITIAL- $=$ ALLOWED PENETRAT $=$ ONE DEPTH $=0.00000000000000$, OFFSET $=0.00000000000000$ OFFSET $-\mathrm{T}=\mathrm{CONSTANT}$ CORNER-C $=$ NO, TBIRTH $=0.00000000000000$ TDEATH $=0.00000000000000$ TIED $=\mathrm{NO}$, TIED-OFF $=0.00000000000000$ HHATTMC $=0.00000000000000$, FCTMC $=0.500000000000000$ FTTMC $=0.500000000000000$ RIGID$\mathrm{TA}=\mathrm{NO}$,

NORMAL-S $=1.00000000000000 \mathrm{E}+11$ TANGENTI $=0.00000000000000$, PTOLERAN $=1.00000000000000 \mathrm{E}-08$ RESIDUAL $=0.00100000000000000$, LIMIT-FO $=1.00000000000000$ ITERATIO=2 TIME-

$\mathrm{PEN}=0.0000000000000$,

CONSISTE=DEFAULT USER-FRI=NO DESCRIPT='NONE',

CFACTOR $1=0.00000000000000$ CS-EXTEN $=0.00100000000000000$,

ALGORITH=DEFAULT RTP-CHEC=NO RTP-

MAX $=0.00100000000000000$,

$\mathrm{XDAMP}=\mathrm{NO}$ XNDAMP $=0.100000000000000$ DISPLACE$=\mathrm{DEFAULT}$,

FRIC-DEL $=$ DEFAULT GAP-VALU $=0.00000000000000$,

EKTMC $=0.00000000000000 \mathrm{GAP}-\mathrm{COND}=0$ GLUEMESH=NO

$*$

CONTACTSURFA NAME $=1$ PRINT $=$ DEFAULT SAVE=DEFAULT

SOLID $=$ MULT BODY $=0$,

ORIENTAT $=$ AUTOMATIC MARQUEEB $=0$ DESCRIPT $=$ 'NONE'

@CLEAR

311

@

*

CONTACTSURFA NAME $=2$ PRINT $=$ DEFAULT $S A V E=$ DEFAULT

SOLID=MULT BODY $=0$,

ORIENTAT $=$ INPUT SENSE $=1$ MARQUEEB $=0$ DESCRIPT $=$ 'NONE

@CLEAR

$1-10$
@

CONTACTPAIR NAME $=1$ TARGET $=2$ CONTACTO $=1$

FRICTION $=0.00000000000000$,

TBIRTH $=0.00000000000000$ TDEATH $=0.00000000000000$, HHATTMC $=0.00000000000000$ FCTMC $=0.00000000000000$, FTTMC $=0.00000000000000 \mathrm{NX}=0 \mathrm{NY}=0 \mathrm{NZ}=0$ OFFSETCO $=\mathrm{BOTH}$, EKTMC $=0.00000000000000 \mathrm{GAP}-\mathrm{COND}=0$

\section{ACKNOWLEDGMENT}

This work was supported by the Grant National Agency VEGA of the Slovak Republic, project No. 1/0006/20.

\section{REFERENCES}

[1] ADINA R \& D "Theory and Modeling Guide", vol. I, ADINA, ADINA R \& D, Inc., Watertown, MA, USA, 2012.

[2] L. Frýba, Vibration of Solids and Structures Under Moving Loads" ACADEMIA, Praha, Nordhoff International Publishing, Groningen, 1972.

[3] M. Reza Eslami, "Finite Elements Method in Mechanics", Springer, vol. 216, 2014, pp. 119-156.

[4] B. Zhu, "The Finite Element Method: Fundamentals and Applications in Civil, Hydraulic, Mechanical and Aeronautical Engineering”, Wiley, 2018

[5] P.L Pasternak, "Osnovy novogo metoda rozčota fundamentalov na uprugnom osnovanii pri pomočši dvuch kueficientov posteli" GIT, Moskva, 1954.

[6] M.R. Madhav, H.B. Poorooshasb, "Modified pasternak model for reinforced soil", Mathematical and Computer Modelling, Elsevier, vol 12, iss. 12, 1989, pp. 1505-1509.

[7] S.L. Barbour and J. Krahn. "Numerical modellingprediction or process", Geotechnical News, vol. 22, iss. 4, 2004, pp. 44-52.

[8] P. Mauro and M. Andres, "Common mistakes about numerical representations", Behavioral and Brain Sciences, vol. 32, iss. 3-4, 2009, pp. 346.

[9] M.N. Sadiku, S.M. Musa, K. Kirby, "Common mistakes made by students", IEEE Potentials, vol. 31, iss.4, 2012, pp. 9-16.

Contribution of Individual Authors to the Creation of a Scientific Article (Ghostwriting Policy)

Jozef Vlček elaborated the theoretical part.

Veronika Valašková is the author of the programs.

\section{Sources of Funding for Research Presented in a Scientific Article or Scientific Article Itself}

This work was supported by the Grant National Agency VEGA of the Slovak Republic, project No. 1/0006/20.

\section{Creative Commons Attribution License 4.0 (Attribution 4.0 International, CC BY 4.0)}

This article is published under the terms of the Creative Commons Attribution License 4.0

https://creativecommons.org/licenses/by/4.0/deed.en_US 